\title{
Experimental study on bond strength of joint surface of double- sided laminated shear wall
}

\author{
Yuan Yiwei ${ }^{1, a}$, Tang Baijian ${ }^{1}$, Li Hongming ${ }^{1}$, Ding Chenchen ${ }^{1}$, Gu Sheng ${ }^{2}$ \\ ${ }^{1}$ Jiangsu University of science and technology, School of civil engineering and architecture, Zhenjiang, Jiangsu, China \\ ${ }^{2}$ Kunshan Construct Engineering Quality Testing Center, Kunshan, Jiangsu, China
}

\begin{abstract}
In order to study the bonding strength of the joint surface of the double-sided laminated shear wall,a double-sided laminated shear wall specimen was designed and fabricated,and then the bars were planted in the precast layer and the middle post pouring layer of the specimen, and the normal tensile bond strength of the joint surface was tested by the drilling core planting bar drawing method. The results show that the bond strength of the joint surface of double-sided laminated shear wall can be detected by the method of drilling core planting bar drawing, and according to the cross section of the core sample, it can be known that the joint surface is indeed the weak part of the laminated member, and it is suggested that the bond strength of the joint surface of the double-sided laminated shear wall should be tested by planting steel bars in the middle post-cast layer.
\end{abstract}

\section{Introduction}

In recent years, my country has been vigorously developing prefabricated buildings ${ }^{[1]}$.As a new fabricated shear wall, double-sided laminated shear wall is fixed by inserting vertical connecting steel bars into the cavity between precast slabs, and then pouring concrete ${ }^{[2]}$, two new and old concrete joint surfaces are formed between post pouring concrete and precast slabs.

However, as far as the fabricated structure is concerned, the joint surface is still the weak part of the fabricated laminated component. The bonding quality of the new and old concrete joint surface of the double-sided laminated shear wall affects the mechanical performance of the overall structure [3]. Therefore, it is particularly important to detect the bonding quality of the joint surface of the double-sided laminated shear wall.

At present, some studies have shown that the bond strength of the joint surface of the assembled component composite floor can be detected by the method of drilling core planting bar drawing ${ }^{[4]}$,because the thickness of the precast layer and the post pouring layer of the composite floor is thick (the thickness of the precast layer and the post pouring layer is usually $70 \mathrm{~mm}+80 \mathrm{~mm}$ ), the chemical bolts can be embedded in the deep position in the post pouring layer when planting bar, so as to avoid the chemical bolts pulling out during the drawing, resulting in the failure to obtain the required strength Data required.However, the thickness of the prefabricated panels of the double-sided laminated shear wall is usually only $50 \mathrm{~mm}$, so how to apply this method to the detection of the bonding strength of the double-sided laminated shear wall will be an innovative idea.

\section{Detection Principle}

The detection principle of drilling core planting bar drawing method is shown in Fig.1,first, plant the bar on the surface of the test piece perpendicular to the joint surface,the end of the chemical bolt should be $10-20 \mathrm{~mm}$ away from the tested joint surface, and then drill the core sample on the surface of the test piece with the center of the plant bar as the center,the drilling depth of the core sample should exceed 15-20 mm of the tested joint surface,and then the core sample is pulled out until the core sample is damaged,at this time, record the ultimate load value of the core sample failure,combine the core sample diameter D and use the formula (1) Calculate the bond strength $f$ of the fracture surface. If the core sample does not break at the joint surface, the calculation result is the actual tensile strength of the damaged layer concrete. If the core sample breaks at the joint surface, the calculation result is the bonding strength of the joint surface.Since the thickness of the prefabricated layer of the conventional double-sided laminated shear wall is about $50 \mathrm{~mm}$,in order to avoid that the required data can not be obtained due to the shallow planting depth, this experiment uses two solutions to bond the joint surface of the double-sided laminated shear wall The strength is tested, as shown in Figure 1 (a) and (b), which are planting bar in the precast layer of the double-sided laminated shear wall and the middle post cast layer.

$$
f=\frac{4 F}{\pi D^{2}}
$$

a1002381930@qq.com 


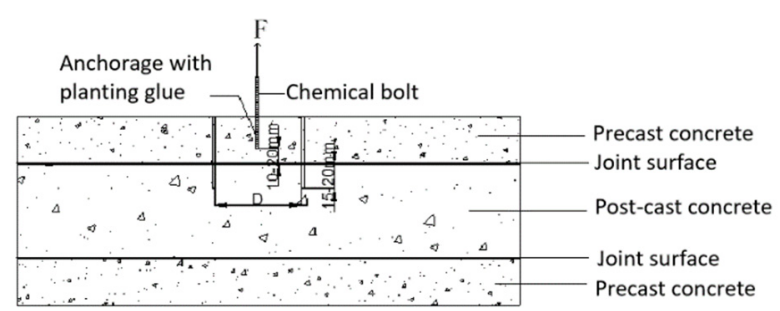

(a)Planting bars in precast layer

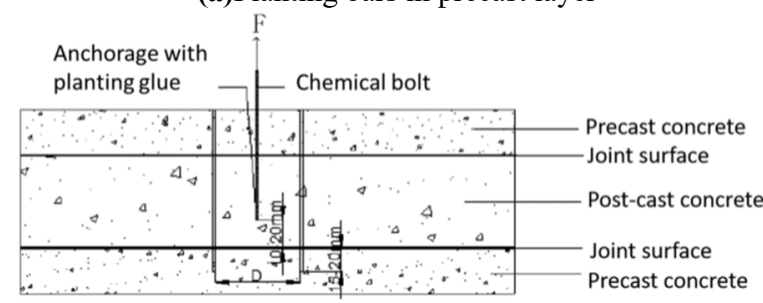

(b)Planting bars in the middle post-pouring layer

Fig. 1. Drilling core planting bar drawing detection principle

\section{Specimen design and experimental verification}

\subsection{Specimen design}

The design of the specimen was based on the actual engineering, referring to the Shanghai "Technical Regulations for Assembling Integral Laminated Shear Wall Structure" (DG/TJ08-2266-2018), and produced a double-sided laminated shear wall specimen.The design is shown in Figure 2(a), and the on-site production is shown in Figure 2(b). The total thickness of the wall is $200 \mathrm{~mm}$, the steel bar in the specimen is HRB400, the concrete strength level is $\mathrm{C} 35$, and the concrete is naturally cured after pouring.

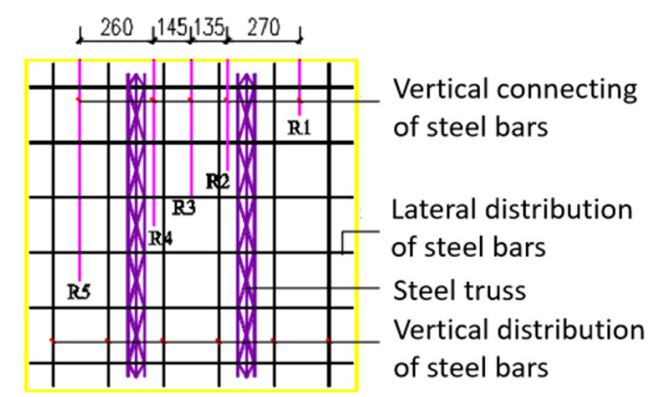

(a)Specimen design drawing

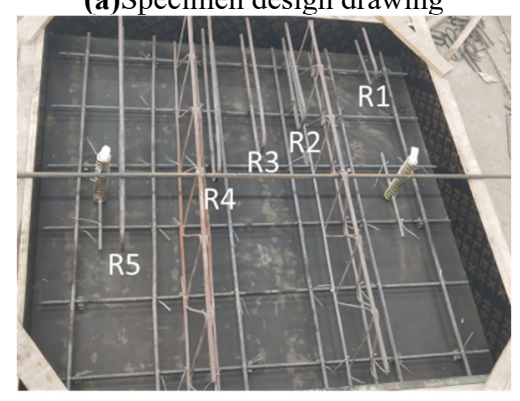

(b)On site drawing

Fig.2.Fabrication of double-sided laminated shear wall specimens

\subsection{Test verification}

The instrument used in this test is the HC-40 multifunctional strength detector, as shown in Figure 3. The instrument consists of a through-core jack, a hand pump, a triangular chassis and a force measuring device.

Before the test, it is necessary to locate the drilling position of the core sample. Since the double-sided laminated shear wall is equipped with distributed steel bars, truss steel bars and vertical connecting steel bars, the approximate positions of distributed steel bars, truss steel bars and vertical connecting steel bars are located according to the design drawing of the test piece and combined with the steel bars scanner to avoid these steel bars positions and locate the drilling position of the core sample, as shown in Figure 4(a), and then mark the planting area in the center of the core sample drilling position, the position of drill the core planting bar is shown in Figure 4 (b) and (c), where in c-1-3, "1" means that the steel planting is in the precast layer, "3" means the third core sample, "2" means that the steel planting is in the middle post cast layer, "4" means the fourth core sample, and the rest of the core samples are explained according to this definition.

The diameter of the chemical bolt used for the planting of steel bar is $12 \mathrm{~mm}$, so the planting hole is $14 \mathrm{~mm}$, the depth of the chemical bolt for planting the steel bar on the precast layer is $35 \mathrm{~mm}$, and the depth of the chemical bolt for planting the steel bar on the middle post-pouring layer is $130 \mathrm{~mm}$. When drilling the core, drill a small core sample with a diameter of $72 \mathrm{~mm}$ with the implanted chemical bolt as the center. The drilling depth of the core sample should penetrate the joint surface $10-20 \mathrm{~mm}$, so the depth of the core sample drilled in the prefabricated layer is $60 \mathrm{~mm}$, the depth of the core sample drilled in the middle post-cast layer is $160 \mathrm{~mm}$, and drilling and planting bar is shown in Figure 5.Finally, the multi-functional strength tester was set up on the surface of the test piece to perform the pull test. The on-site pull test is shown in Figure 6 .

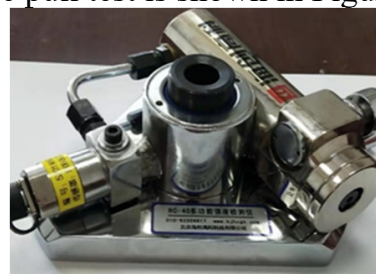

Fig.3. Multifunctional strength detector

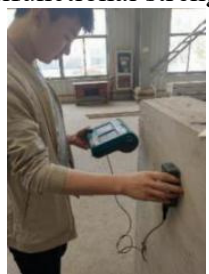

(a)Locating steel bar

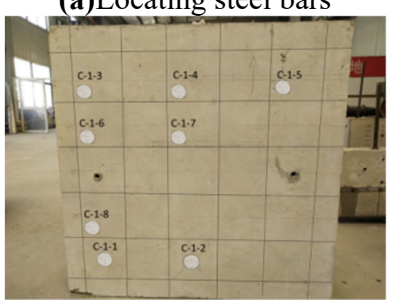

(b)Drilling core planting point on the front of the specimen 


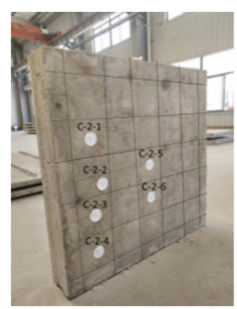

(c)Drilling core planting point on the back of the specimen

Fig.4. Locate the drill core planting point

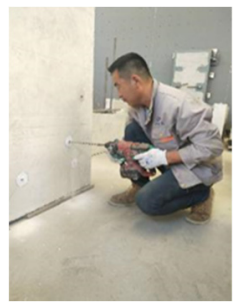

(a)drilling

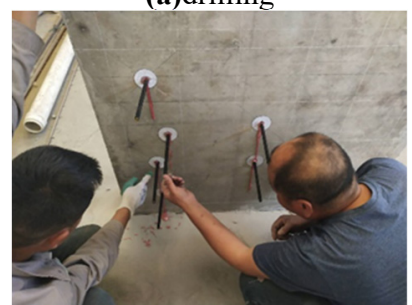

(b)Planting bar

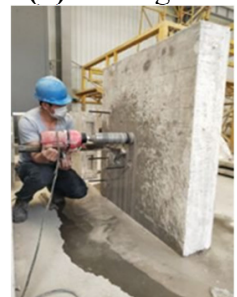

(c) Drill core sample

Fig.5. Drilling core planting steps

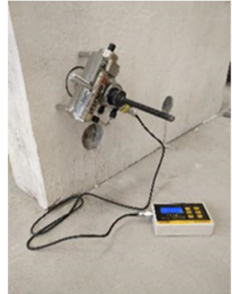

Fig.6. On-site pull test

\section{Analysis of test results}

\subsection{Destruction form}

In the pull-out test of 8 core samples of the prefabricated layer, the C-1-1 and C-1-5 core samples have cross-section brittle fracture in the prefabricated layer, and the height of the core samples is between $40 \mathrm{~mm} \sim 50 \mathrm{~mm}, \mathrm{C}-1-2$ core sample suffered brittle fracture failure at the joint surface, and the other core samples had chemical bolt pull-out failure,chemical bolt pull-out failure accounted for $62.5 \%$ of the core samples detected in the prefabricated layer, indicating that planting steel bar in precast layer for drawing cannot effectively detect the bonding strength of the joint surface of the double-sided laminated shear wall;

In the pull-out test of the core samples of the middle post pouring layer, except c-2-1, the chemical bolt pull-out failure occurred due to the unsteadiness of the steel planting glue, the other core samples were brittle fracture at the joint surface, and the fracture surface was saw tooth shape, which was an effective failure, accounting for $83.3 \%$ of the total, and the height of the core samples was about $15 \mathrm{~cm}$, indicating that the post-pouring It is feasible to detect the bonding strength of the joint surface of the double-sided laminated shear wall by layer-planting bar drawing. The typical failure pattern of core sample is shown in Figure 7.

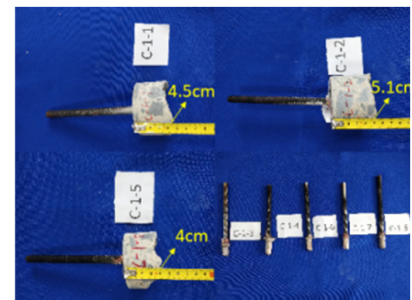

(a)Typical drawing of prefabricated layer implanted bar

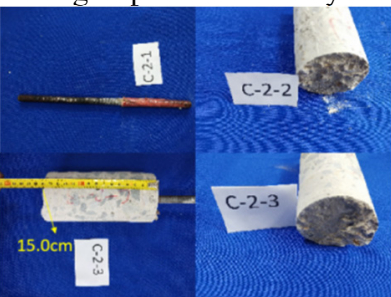

(b)Typical drawing of post-pouring layer planting bar Fig.7.Typical diagram of core sample failure

\subsection{Test and Analysis of Bonding Strength of joint surface}

The test results are summarized in Table 1.The concrete strength level of the specimen is C35,C-1-1 and C-1-5 occurred brittle fracture failure in the precast layer,at this time, it was detected that the axial tensile strength of the precast layer concrete was $3.18 \mathrm{MPa}$ and $2.1 \mathrm{MPa}$, and the average value was $2.64 \mathrm{MPa}$. The bonding strength of the joint surface detected by the planting bar drawing is lower than the measured concrete axial tensile strength, indicating that the joint surface is indeed the weak part of the fabricated composite member.

Table 1. Summary of test results

\begin{tabular}{|c|c|c|c|c|c|c|}
\hline number & $\begin{array}{c}\text { Planting } \\
\text { bars layer }\end{array}$ & Fracture layer & $\begin{array}{c}\text { Core } \\
\text { sample } \\
\text { height } / \mathbf{m m}\end{array}$ & $\begin{array}{c}\text { Ultimate } \\
\text { load value } \\
/ \mathbf{k N}\end{array}$ & $\begin{array}{l}\text { Cross section } \\
\text { area of core } \\
\text { sample } / \mathbf{m m}^{2}\end{array}$ & $\begin{array}{c}\text { Bond strength of } \\
\text { failure surface } \\
\mathrm{N} / \mathrm{mm}^{2}\end{array}$ \\
\hline C-1-1 & \multirow{4}{*}{$\begin{array}{c}\text { Prefabricated } \\
\text { layer }\end{array}$} & Prefabricated layer & $30-40$ & 12.95 & \multirow{4}{*}{$36 \times 36 \times \pi$} & $3.18 \mathrm{MPa}$ \\
\hline C-1-2 & & Joint surface & $46-52$ & 11.63 & & $2.86 \mathrm{MPa}$ \\
\hline$C-1-3$ & & $\begin{array}{l}\text { Chemical bolt } \\
\text { pullout }\end{array}$ & / & 8.97 & & / \\
\hline C-1-4 & & Chemical bolt & 1 & 8.43 & & 1 \\
\hline
\end{tabular}




\begin{tabular}{|c|c|c|c|c|c|}
\hline & & pullout & & & \\
\hline C-1-5 & & Prefabricated layer & $30-40$ & 8.53 & $2.1 \mathrm{MPa}$ \\
\hline$C-1-6$ & & $\begin{array}{l}\text { Chemical bolt } \\
\text { pullout }\end{array}$ & l & 8.22 & I \\
\hline C-1-7 & & $\begin{array}{l}\text { Chemical bolt } \\
\text { pullout }\end{array}$ & l & 6.7 & l \\
\hline C-1-8 & & $\begin{array}{l}\text { Chemical bolt } \\
\text { pullout }\end{array}$ & / & 8.12 & l \\
\hline C-2-1 & \multirow{6}{*}{$\begin{array}{l}\text { Middle post- } \\
\text { cast layer }\end{array}$} & $\begin{array}{c}\text { Uncured planting } \\
\text { glue }\end{array}$ & I & I & l \\
\hline C-2-2 & & Joint surface & $147-150$ & 6.47 & $1.59 \mathrm{MPa}$ \\
\hline C-2-3 & & Joint surface & $149-153$ & 10.12 & $2.49 \mathrm{MPa}$ \\
\hline $\mathrm{C}-2-4$ & & Joint surface & $150-155$ & 9.16 & $2.25 \mathrm{MPa}$ \\
\hline $\mathrm{C}-2-5$ & & Joint surface & $148-150$ & 10.67 & $2.62 \mathrm{MPa}$ \\
\hline C-2-6 & & Joint surface & $150-160$ & 9.79 & $2.41 \mathrm{MPa}$ \\
\hline
\end{tabular}

\section{Conclusion}

(1) It is feasible to use the drill core planting bar drawing method to detect the bonding strength of the double-sided laminated shear wall joint surface. This method is convenient and quick, with high detection accuracy and strong adaptability.

(2) The bonding strength of the joint surface of doublesided laminated shear wall is detected by planting steel bars in the precast layer, which is prone to chemical bolt pull-out failure and unable to obtain effective data. Therefore, it is suggested that the method of planting steel bars in the middle post cast layer should be used in the actual project to detect the bonding strength of the joint surface.

(3) The experimental results show that, on the premise of ensuring that the drilling position exceeds the measured joint surface, the bond strength of the joint surface detected by the core sample section at the joint surface of the new and old concrete is lower than the measured axial tensile strength of the concrete, which indicates that the joint surface is indeed the weak part of the fabricated composite member.

\section{References}

1. Huang, W. Sun, Y. Zhang, J. Fan,Z. Ma, X. (2020) Research Status on new connection technology of assembled wall structure. J. Industrial Architecture: 113.

2. Zhang, H. Ma, Q. (2016) Design technology research and engineering application of double-layer superimposed slab shear wall structuresp. J. Architecture Structure, 46(10): 1-8.

3. Zhang, W. Yang, L. Zhang, Q, Cui, Jiachun. (2018) Research on key issues of double-sided laminated shear wall: seismic performance test of horizontal connection nodes. J. Journal of Civil Engineering, 51(12): 28-41.

4. Zhang, J. Sun, B. Mao, S. Wang, N. Zhang, Y. (2018) Experimental study on bond strength of concrete interface in prefabricated structure. J. Architecture Structure. 48(23):17-21+27. 